NASA Technical Memorandum 104050

\title{
DYNAMIC RESPONSE OF A HAMMERHEAD LAUNCH VEHICLE WIND-TUNNEL MODEL
}

\author{
(NASA-TM-104050) OYNAMIC RESPONSE DF A \\ N91-21177 \\ HAMMERHEAO LAUNCH VEHICLE WIND-TUNNFL HOUEL \\ (NASA) 12 p \\ CSCL 229 \\ $\begin{array}{ll} & \text { Unclas } \\ 03 / 15 & 0002694\end{array}$
}

Stanley R. Cole

Thomas L. Henning

February 1991

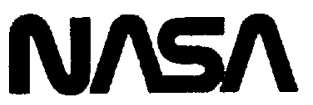

National Aeronautics and Space Administration

Langloy Pesearch Conter Hampton, Virginia 23665 
$\ldots$

$$
\div \ldots
$$




\title{
DYNAMIC RESPONSE OF A HAMMERHEAD LAUNCH VEHICLE WIND-TUNNEL MODEL
}

\author{
Stanley R. Cole \\ NASA Langley Rescarch Center \\ Hampton, VA 23665-5225 \\ Thomas L. Henning \\ General Dynamics Space Systems Division \\ San Dicgo, CA 92138
}

\section{Abstract}

A wind-tunnel test of a 1/10th-scale Atlas-Centaur I Large Payload Fairing launch vehicle model has been conducted in the NASA Langley Transonic Dynamics Tunnel. The wind-tunnel model was an aeroclasticallyscaled version of the flight vehicle and was capable of simulating either of the first two bending vibration modes of the full-scale vehicle by a partial mode technique. The primary purpose of the test was to gather data concerning buffet response which could be used to clear the vehicle for flight. Additionally, angle-of-attack studies were conducted and several payload fairing configurations werc tested to assess the buffet response and dynamic stability of off-design flight conditions and gcometric parameters. No dynamic instabilities were found for any of the configurations tested. The buffet response data for the nominal flight configuration indicate that the unsteady buffet loads represent 5-10 percent of the total design load and, therefore, the buffet loads are not a large factor affecting the overall vehicle design. Payload fairing length-to-diameter ratio variations were found to have small effects on the buffet response of the model, except in the case of the smallest length-10-diameter ratio in the second bending mode configuration. This configuration experienced much greater transonic buffeting relative to the other length-to-diameter models for the second bending mode simulation. The effects of angle of attack on buffet response were found to be small. The model was more sensitive to Mach number changes than to angle of attack. The buffet response results from this wind-tunnel test were influenced by the tunnel facility vibration levels. An attempt was made to expcrimentally reduce the effect of the facility mechanical vibration for the nominal flight configuration by testing with vertical rods used to stiffen the sting support. The first flight of the Atlas-Centaur I
\end{abstract}

vchicle successfully occurred on July 25,1990 and a comparison of flight measurements with wind-tunnel data is presented in this paper. The flight data was found to be well within the $3 \sigma$ level of the wind-tunnel data.

\section{Nomenclature}

A payload fairing cross-sectional (frontal) area, in ${ }^{2}$

$\mathrm{C}_{\sigma}$ bending moment coefficient $=\frac{\sigma}{\mathrm{qAD}}$

D maximum payload fairing diameter, in

f frequency, $\mathrm{H} \%$

$\mathrm{H}$ length, in

L payload fairing cylindrical section length, in

m generalized mass, slugs

M Mach number

$P \quad$ wind-tunnel drive power consumption, watts

$\bar{P} \quad P$ normalized to $P$ at $M=1.2$

q dynamic pressure, $\mathrm{lb} / \mathrm{in}^{2}$

$\mathrm{V}$ velocity, in/sec

$x$ body station, in

$\mathrm{z}$ modal deflection normalized to maximum deflection

$z$ vertical acceleration of sting support sector, $\mathrm{g}$

$\bar{z} \quad \dot{z}$ normalized to $\ddot{z}$ at $\mathrm{M}=1.2$

$\alpha \quad$ angle of attack, degrees

$\rho \quad$ fluid density, $\mathrm{lb} \cdot \mathrm{sec}^{2} / \mathrm{in}^{4}$

$\sigma \quad$ root-mean-square bending moment, in $\cdot \mathrm{lb}$

(1) wind-tunnel drive rotational speed, $\mathrm{Hz}$

$\bar{\omega} \quad \omega$ normalized to $\omega$ at $\mathrm{M}=1.2$

\section{Subscripts:}

i $\quad i^{\text {th }}$ vibration mode

$v \quad$ full-scale vehicle

w wind-tunnel model 


\section{Introduction}

Ever increasing sizes and weights of launch vehicle payloads have resulted in an effort to provide a larger payload capability for the Atlas-Centaur launch vehicle (figure 1). The original Atlas-Centaur payload bay external diameter was the same as the propulsion stages of the launch vehicle. The new design, known as the AtlasCentaur I Large Payload Fairing configuration (hereafter referred to as the Atlas-I LPF), has a 37.5 percent larger external diameter payload fairing. This new "hammerhead" payload fairing raised questions as to the unsteady aerodynamic loadings which might develop in flight. The NASA space vehicle design criteria specified in reference 1 would classify the Atlas-I LPF configuration as "buffet prone" compared to the baseline Atlas-Centaur which would be classified as a "clean body of revolution". Furthermore, wind-tunnel test results documented in reference 2 indicate a relationship between payload fairing cylinder length-to-diameter (L/D) ratios and vehicle stability. A Titan III hammerhead configuration with an $\mathrm{L} / \mathrm{D}=0.4$ was shown to be unstable during that test. In order to correct this instability, the model L/D was increased to 1.1. A drawing of the eventual flight configuration of the Titan III concept is shown in figure 1 as the Titan-Centaur with an $L / D=3.1$. Other launch vehicles are shown in figure 1 , such as the original AtlasCentaur and the Atlas-I LPF, for comparison. The Atlas-I LPF configuration does not have the flow complexities associated with the large solid rocket motors of the Titan III configuration as shown in figure 1 , however, the $L / D$ ratio of the large payload fairing is 1.0. While the previous wind-tunnel test results do not provide sufficient data to define stability criteria for $0.4<L / D<1.1$, they do indicate potential stability problems for configurations in this range. These launch vehicle stability and buffet response phenomena are not easily predictable by analysis, although significant advances are being demonstrated through computational fluid dynamic techniques, such as documented in reference 3. Due to concerns about these phenomena, a wind-tunnel test was performed to determine such effects on the overall vehicle response of the Atlas-I LPF.

An aeroelastically-scaled model of the Atlas-I LPF vehicle was constructed for wind-tunnel testing in the NASA Langley Transonic Dynamics Tunnel. The primary objectives of the wind-tunnel test were to verify that the Atlas-I LPF configuration was aeroelastically stable and to determine the overall vehicle bending moments due to buffet expected during transonic flight. A secondary objective was to conduct a parametric study to determine the effect of various hammerhead fairing configurations (in addition to the nominal design) on model response.

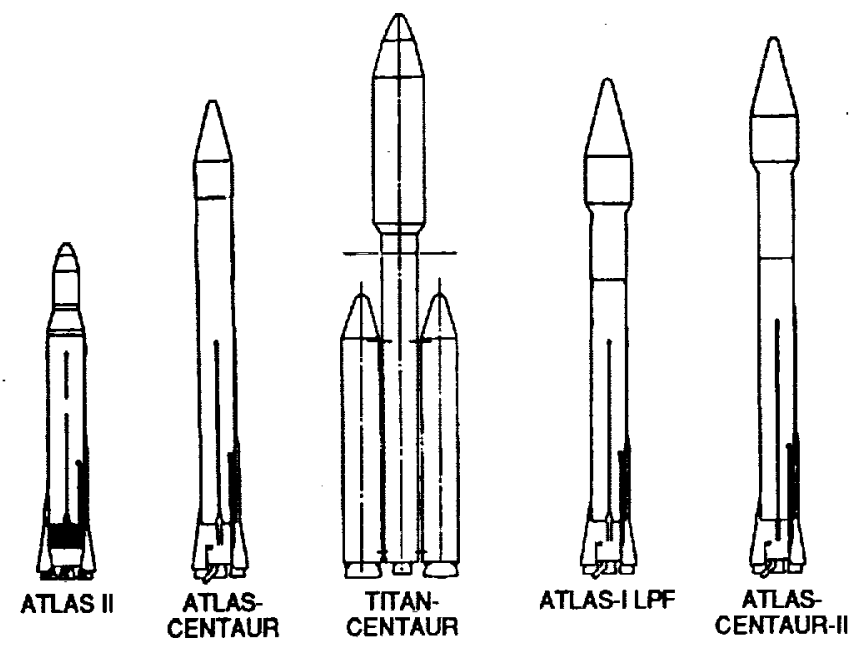

Fig. 1- Drawing of several launch vehicles.

The purpnses of this paper are to document general details of the model construction and to present some of the wind-tunnel test results. These results include the effects of various payload fairing configurations on the dynamic response of the model, interpretations of the response for the nominal flight configuration $(\mathrm{L} / \mathrm{D}=1.0)$, and an assessment of the influence of the sting mount system which was used for this test. Additionally, some full-scale vehicle results from the first flight of the Atlas-I LPF vehicle are presented and compared with wind-tunnel test results. The first flight of the Atlas-I LPF occurred on July 25,1990 . A photograph of the vehicle at the launch pad facility is shown in figure 2 .

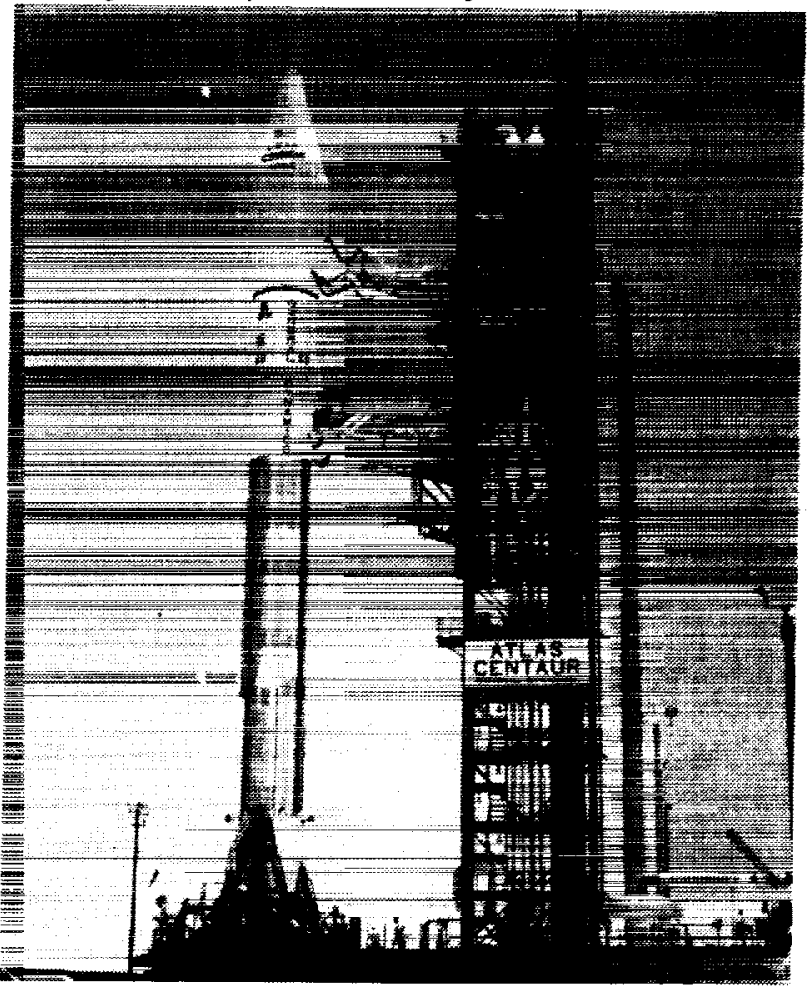

Fig. 2- Photograph of Atlas-I LPF flight vehicle at the launch pad facility. 


\section{Wind Tunnel}

The experimental study was conducted in the NASA Langley Transonic Dynamics Tunnel (TDT) ${ }^{4}$. The TDT is specifically designed for studying aeroelastic phenomenon. The facility is a continuous circuit wind tunnel capable of testing at total pressures from about 0.1 to 1.0 atmospheres and over a Mach number range from zero to 1.2. The test section of the TDT is $16.0 \mathrm{ft}$ square with cropped comers. Testing can be conducted in the TDT using either air or a heavy gas (dichlorodifluoromethane) as the test medium. The Atlas-I LPF model was aeroelastically scaled for and tested in the heavy gas. A unique safety feature of the TDT is a group of four bypass valves connecting the test section area (plenum) of the tunnel to the retum leg of the wind-tunnel circuit. In the event of a model instability, such as severe buffeting, these quick-actuating valves can be opened. This causes a rapid reduction in the test section Mach number and dynamic pressure. Operation of the bypass valves was never required for the model configurations tested. The combination of large scale, high speed, high density, variable pressure, and the bypass valve system makes the TDT ideally suited for testing aeroelasticallyscaled models such as the Atlas-I LPF model.

\section{Wind-Tunnel_Model}

A photograph of the 1/10th-scale Atlas-I LPF model mounted in the TDT test section on the centerline sting support is shown in figure 3 . As can be seen, this model is a forebody representation of the flight vehicle. The forebody model was scaled to the wind-tunnel size at an operating condition of $\mathrm{M}=0.9$ and $\mathrm{q}=300 \mathrm{lb} / \mathrm{ft}^{2}(2.083$ $\mathrm{lb} / \mathrm{in}^{2)}$ by nondimensional length, time, and mass variables. The length was scaled based on blockage restrictions in the TDT to

$$
\frac{\mathrm{H}_{\mathrm{w}}}{\mathrm{H}_{\mathrm{v}}}=0.10
$$

The frequency (time) relationship between wind-tunnel scale and full scale was derived from the Strouhal number equivalence

$$
\left\{\frac{\mathrm{fH}}{\mathrm{v}}\right\}_{w}=\left\{\frac{\mathrm{fH}}{\mathrm{v}}\right\}_{v}
$$

which leads to the relationship

$$
\frac{f_{w}}{f_{v}}=\frac{H_{v} V_{w}}{H_{w} V_{v}}=10 \frac{V_{w}}{V_{v}}=4.5
$$

The mass of the wind-tunnel model was based on the nondimensional mass ratio defined as

$$
\left\{\frac{m}{\rho H^{3}}\right\}_{w}=\left\{\frac{m}{\rho H^{3}}\right\}_{v}
$$

which leads to the relationship

$$
\frac{m_{w}}{m_{v}}=\frac{H_{w}^{3} \rho_{w}}{H_{v}^{3} \rho_{v}}=0.001 \frac{\rho_{w}}{\rho_{v}}=0.00225 .
$$

The payload fairing configuration shown in figure 3 is the nominal design for the full-scale flight vehicle $(L / D=1.0)$. The length and diameter dimensions of the payload fairing are indicated on the $\mathrm{L} / \mathrm{D}=1.0$ configuration drawing of the Atlas-I LPF model body in figure 4. For the parametric study of the effects of the payload fairing L/D ratio, model configurations were tested with $L / D$ ratios of $0.3,0.6$, $0.8,1.0$, and 1.2. Drawings of these various configurations are shown in figure 5 .

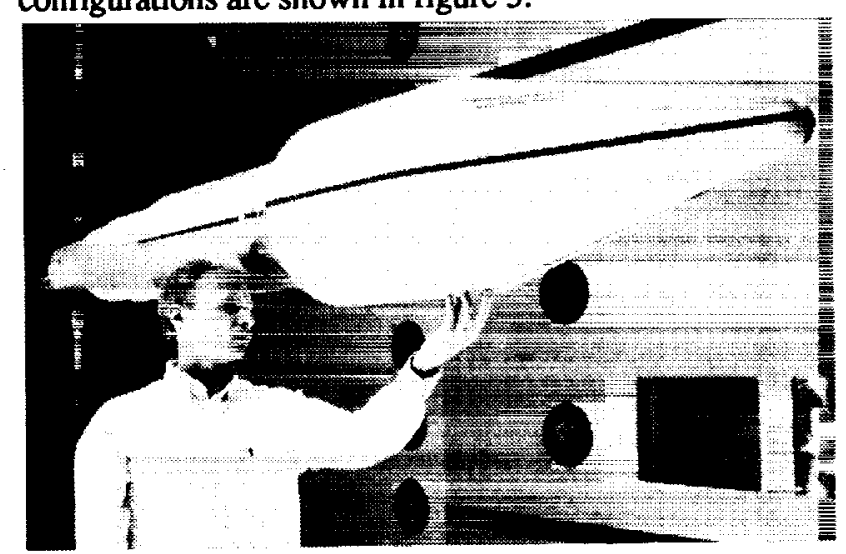

Fig. 3- Photograph of model mounted in the TDT.

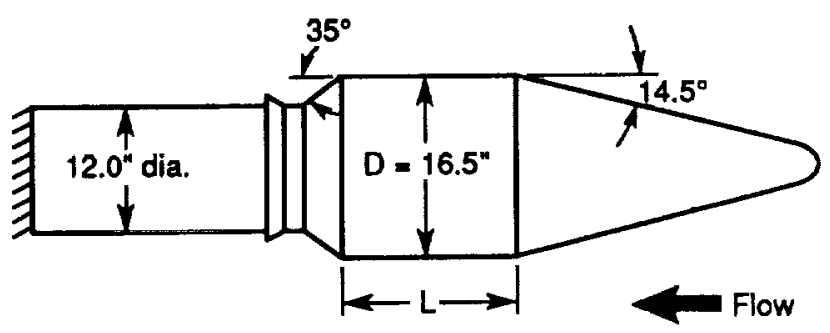

Fig. 4- Drawing of model showing fairing dimensions.

More details on the construction of the Atlas-I LPF model are shown in figure 6 . The payload fairing portion of the wind-tunnel model was constructed of foam-lined fiberglass forms. A cylindrical section of the payload fairing could be replaced with different length cylinders to vary the fairing ratio from $L / D=0.3$ to $L / D=1.0$. An extension skirt mounted at the aft end of the $L / D=1.0$ payload fairing provided the $L / D=1.2$ configuration. 
Variable weights were available in the payload fairing and in the model aft of the payload fairing (see figure 6) so that the total weight and weight distribution of the model could be adjusted with each L/D configuration to properly scale to the full-scalc flight vehicle. Another special feature of the model was an internal hydraulic braking system (figure 6) which was intended to suppress excessive motion should the model experience severe buffeting or a divergent dynamic instability.
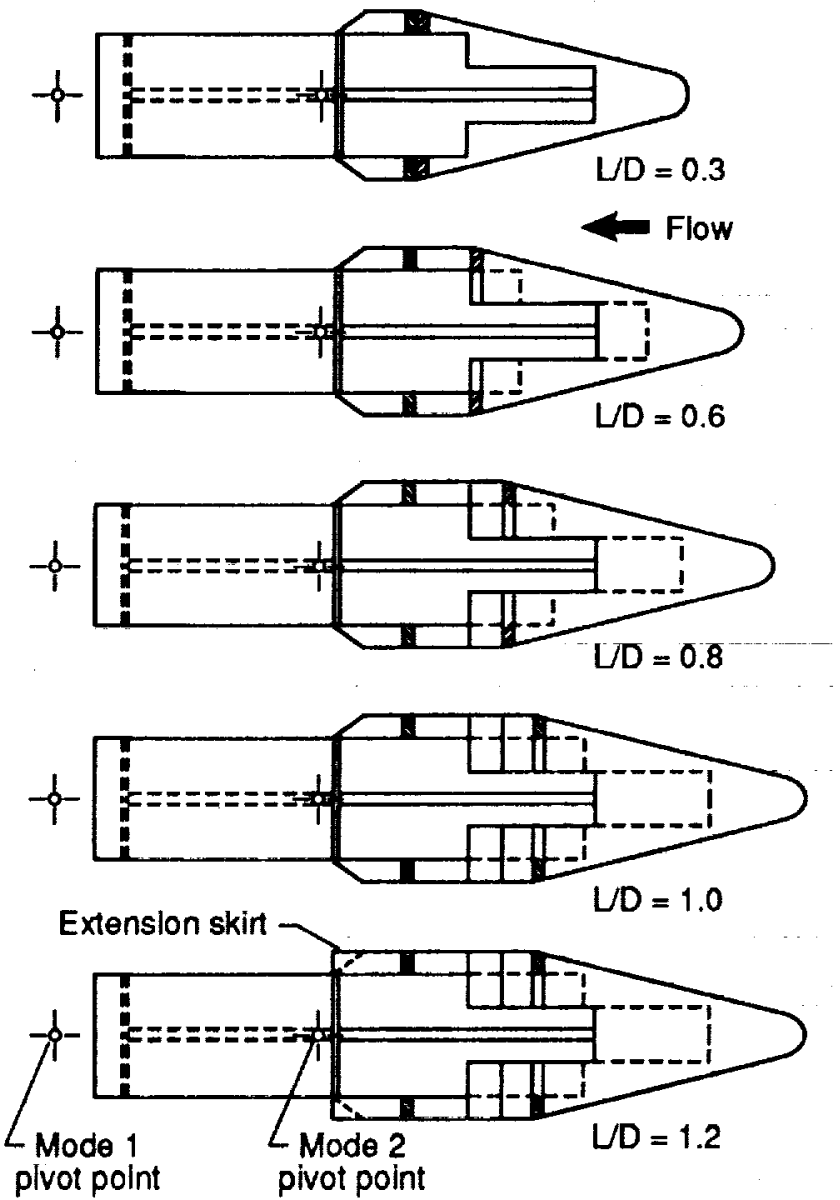

Fig. 5- Payload fairing configurations.

\section{Cartial Mode_Simulation}

The wind-tunnel model configurations were dynamically scaled to simulate either the first or second vehicle bending modes during transonic flight. This partial mode testing technique ${ }^{5}$ was developed at the NASA Ames Research Center and was used in the Ames 14-ft Transonic Wind Tunnel. The primary assumptions for this simulation are that, for a typical launch vehicle, the mode shape forward of the first node point can be considered linear and that the majority of the unsteady acrodynamic forces are introduced through the forward portion of the vehicle. Thus, a forebody model can be used to simulate the important structural dynamic properties and the majority of the unsteady acrodynamics of the entire launch vehicle. Figure 7 shows calculated mode shapes for a forward portion of the full-scale Atlas-I LPF vchicle for the first two modes. The mode shapes forward of the first node point are seen to be nearly linear. The Atlas-1 LPF model was constructed to geometrically model the forward portion of the flight vehicle with a single pivot point (see figure 6) about which to simulate the structural dynamics of a given vibration mode forward of the first node point. The wind-tunnel model design mode shapes for the first two modes are also indicated on figure 7. The wind-tunnel models represent the linear (rigid) portion of the mode shapes forward of the first node point. Based on the assumptions used in the partial mode testing technique conceming the unsteady aerodynamic loading, the generalized mass of the wind-tunnel model is scaled from the generalized mass of the entire flight vehicle. Provisions were made to allow the model to be moved relative to the dynamic pivot point (see figure 8) and to redistribute the internal weight so that the frequencies and generalized mass of the first or second bending mode could be appropriately simulated.

Some difficulty was experienced in correctly modeling thesc two mode shapes in the wind tunnel due to sting support flexibility. Vertical stiffening rods were attached to the sting support to help this situation. Figure 9 shows the effect of the stiffening rods on the first bending mode shape. The mode shapes shown in figure 9 have been normalized to the maximum measured deflection. With the stiffening rods installed, the pivoting motion of the model occurred about a point much closer to the intended rotation point than without the rods installed. This effect was much more pronounced in the first bending mode configuration due to the longer moment arm aboul which the model can rotate on the sting support system. Tests were conducted for both of the primary vibration modes with and without the vertical support rods installed in the tunnel. Although the rods-installed configuration is a slightly better representation of the flight vehicle, most of the testing was conducted for the second bending mode configuration without the rods installed to allow angle of attack variations of the model and to decouple the model from a closely-spaced sting mode.

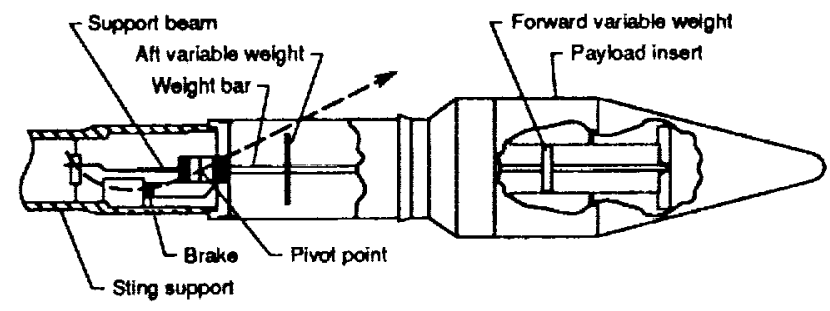

Fig. 6- Drawing showing model details. 


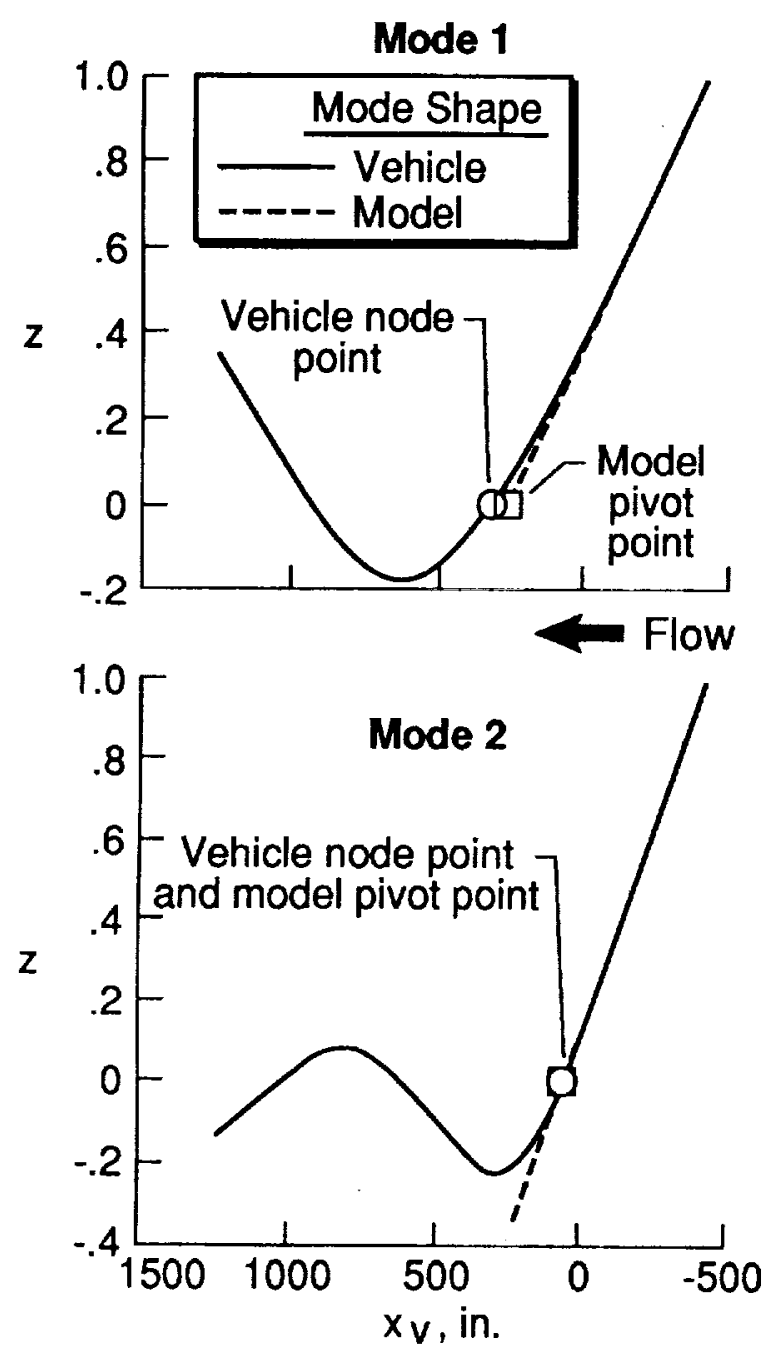

Fig. 7- Vehicle mode shapes and linearized model mode shapes (scaled to flight) utilized for partial mode simulation.

\section{Vibration Characteristics}

The structural dynamic properties of the $1 / 10$ th-scalc Atlas-I LPF model were determined by ground vibration tests with the model mounted in the test section of the TDT. Vibration tests were conducted for the model in the first bending mode configuration and in the second bending mode configuration. The objectives of the vibration lests were to tune the model to the desired test frequency, to determine model mode shapes, and to obtain structural damping of the model for use in scaling of the test data to the full-scale vehicle values. The wind-tunnel model was tuned to $f_{1}=9.8 \mathrm{~Hz}$ for the simulation of the first bending mode and to $f_{2}=25.0 \mathrm{~Hz}$ for the second bending mode. Measured model normalized mode shapes for the simulation of the first two flight modes are shown in figure 8 .

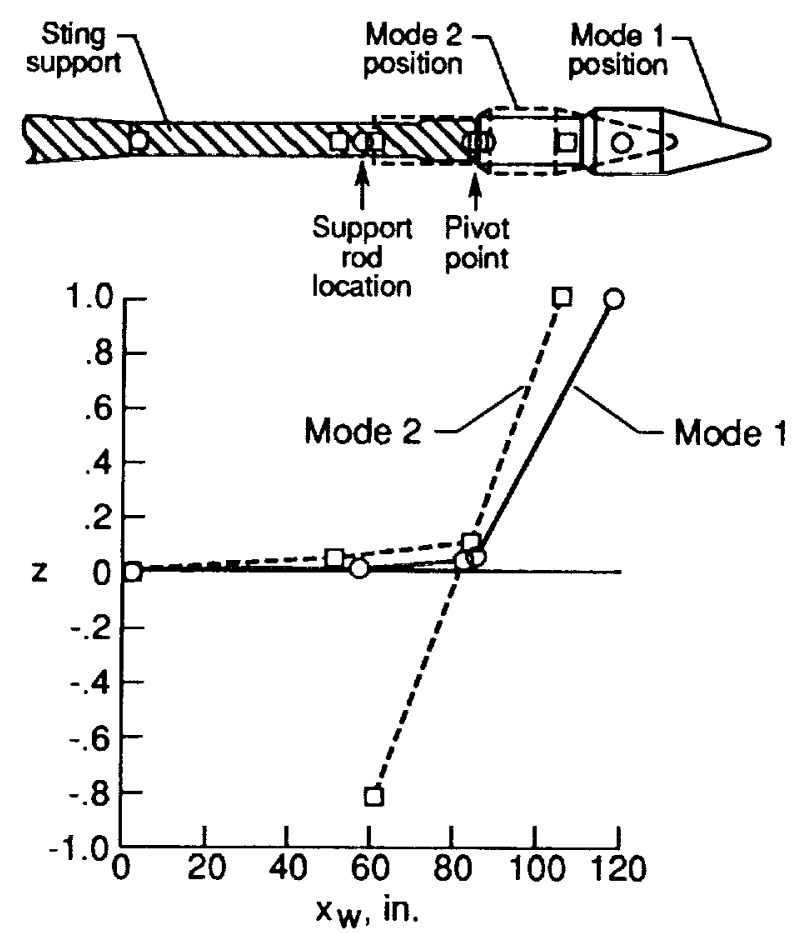

Fig. 8- Normalized mode shapes (with stiffening rods installed) and a drawing indicating position of payload fairing relative to pivot point for both mode simulations.

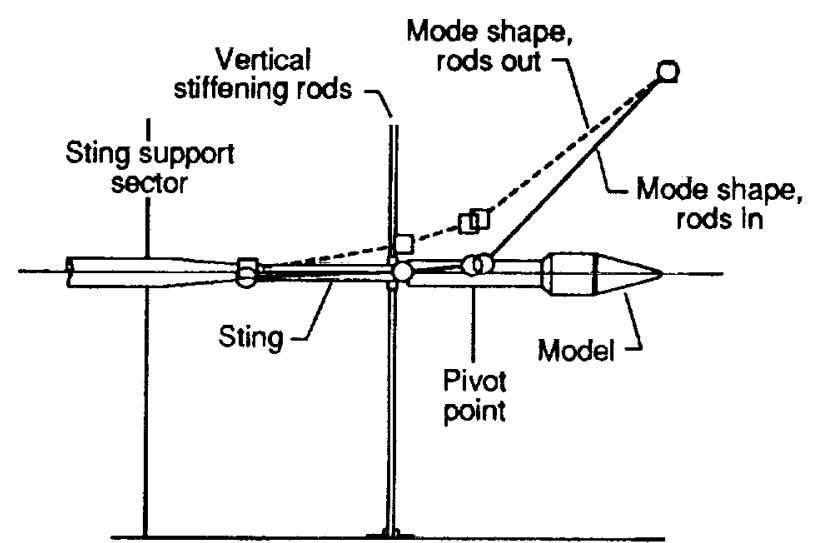

Fig. 9. Drawing of model with vertical stiffening rods installed showing the effect of the rods on the first bending mode shape (normalized).

\section{Instrumentation/Data Acquisition}

The wind-tunnel model was instrumented with pressure transducers, accelerometers, and strain-gauge bridges for the dynamic data acquisition. There were twenty dynamic pressure transducers installed which could be mounted at 23 different locations on the model. The pressure transducer mounting locations are shown in figure 10. There were five biaxial accelerometers located in the model and on the model support sting. These accelerometers were capable of measuring vertical and latcral accelerations. Three of these five accelerometers were mounted within the model. The model was 
instrumented with two pitch bending moment strain-gaugc bridges and with one yaw bending moment strain-gauge bridge near the pivot point. The accelerometer and straingauge bridge locations in the model are also shown in figure 10. Some of these instruments were monitored during the wind-tunnel test via strip chart recorders and a spectral analyzer. Signals from a subset of the instruments were also recorded on analog tape for post-test analysis.

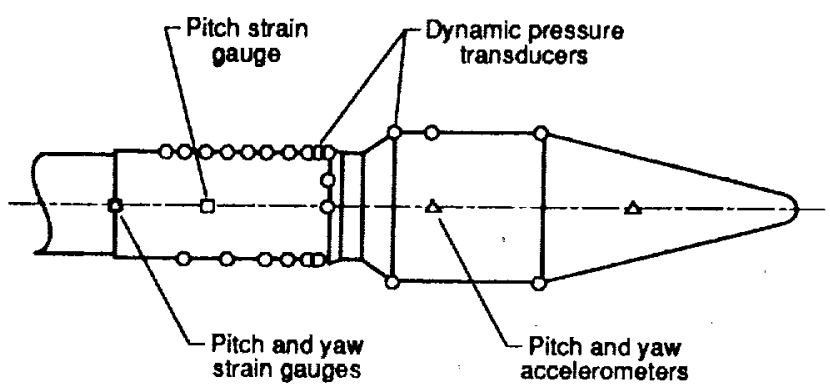

Fig. 10. Drawing of model indicating locations of instrumentation.

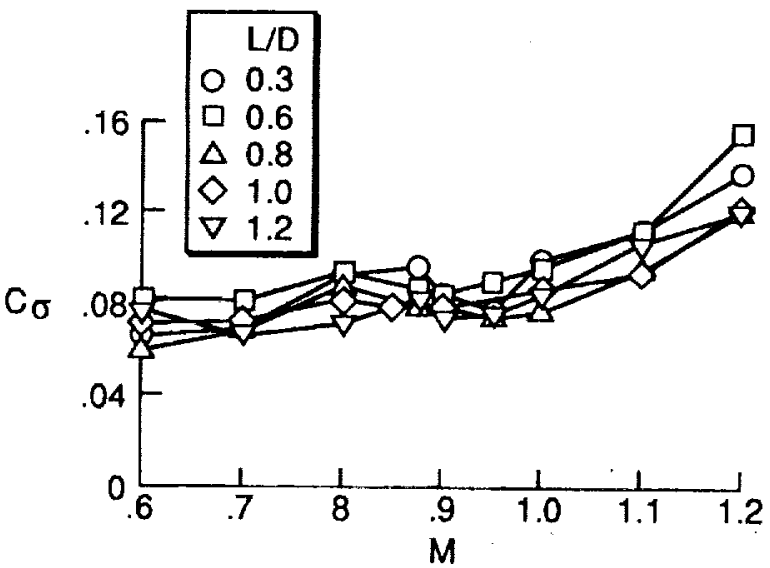

Fig. 11- Effects of L/D variations on buffet response for the first bending mode configuration without the vertical stiffening rods installed.

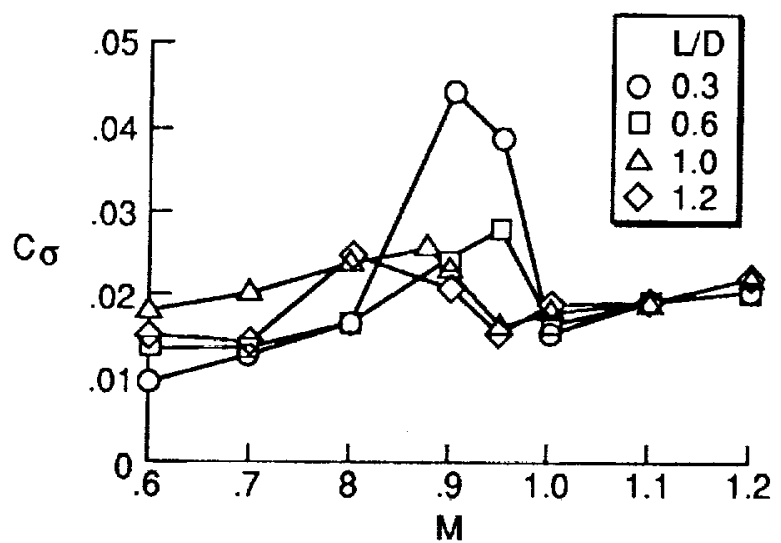

Fig. 12- Effects of L/D variations on buffet response for the second bending mode configuration without the vertical stiffening rods installed.

\section{Results And Discussion}

Wind-tunnel test results obtained using a $1 / 10$ th-scale Atlas-I LPF model have been used to verify the full-scale vehicle aeroelastic stability and to define induced bending moments. The $\mathrm{L} / \mathrm{D}=1.0$ (rods-installed) configuration was the best available simulation of the flight vehicle and has shown that the flight vehicle will be free of dynamic instabilities and will experience acceptable buffet levels during flight. The scaled buffet loads found in the windtunnel test represent approximately 5-10 percent of the total vehicle design load, depending on the flight condition. In addition to flight clearance, some parametric studies were conducted during the wind-tunnel test. These studies include payload cylinder L/D variations and angleof-attack variations for both of the primary vehicle bending modes that could be simulated by the model. The majority of these studies were conducted without the vertical rods installed to allow the angle of attack to be changed without entcring the wind-tunnel test section. None of the configurations tested exhibited a dynamic instability.

\section{L/D Variations}

A number of configurations were tested to assess the effect of the L/D geometry parameter on the buffet response and dynamic stability of the Atlas-I LPF model. Figure 11 shows some of the acquired data for the first bending mode configuration without the vertical stiffening rods installed. The differences in the buffeting responses of the various $L / D$ configurations of figure 11 are relatively small when considering the relationship of these data to the scaled design load capability of the flight vehicle. There is some indication that the lower L/D configurations induced greater buffet response, but the data are not entirely consistent concerning this trend. Prior to the test, it was expected that the model response would peak in the range of $0.80 \leq \mathrm{M} \leq 0.95$ based on past experiences with launch vehicle unsteady loads. Figure 11 shows that the model cxhibited a slight local peak in response near $\mathrm{M}=0.80$ for all of the $\mathrm{L} / \mathrm{D}$ configurations except $\mathrm{L} / \mathrm{D}=0.3$, which peaked closer to $\mathrm{M}=0.87$. But the wind-tunnel data further show that, after this slight peak, the response simply continues to grow with increasing Mach number. (Testing beyond $M=1.2$ was not possible duc to the opcrating capabilities of the TDT.) This response increase was not expected and is discussed further in the wind-tunnel influence sub-section.

The response of the second bending mode configuration to $\mathrm{L} / \mathrm{D}$ variations is shown in figure 12 , again without the vertical stiffening rods installed. For the second bending mode, the response is found to peak in the Mach number range of $0.80 \leq \mathrm{M} \leq 0.95$, but the response appears to be continuing to increase with Mach number as the tunnel operating limits are reached at 
$M=1.2$, as occurred with the first bending mode configuration. A subtle difference in the response due to the L/D variations is that there generally appears to be a slight increase (based on the Mach number trends of figure 12) in the Mach number at which the peak response occurs as the $L / D$ is decreased. The $L / D=0.3$ configuration of figure 12 (second mode) is the one configuration that shows a substantial increase in the dynamic response relative to the other $L / D$ configurations. This may be an indication that the smallest L/D configuration tested was approaching a dynamic instability condition. Although the current state-of-the-art analysis techniques are unable to predict this type of phenomena, various mechanisms which can drive an aeroelastic instability have been proposed in reference 6 . These mechanisms suggest that the added buffet effects of the large solid rocket motors on the Titan III wind-tunnel model may have contributed to the unstable response observed in that test (reference 2) as discussed in the introduction of this paper. In addition, similar mechanisms described in reference 6 may be used to describe the increased response levels measured for the L/D $=0.3$ Atlas-I LPF configuration described above.

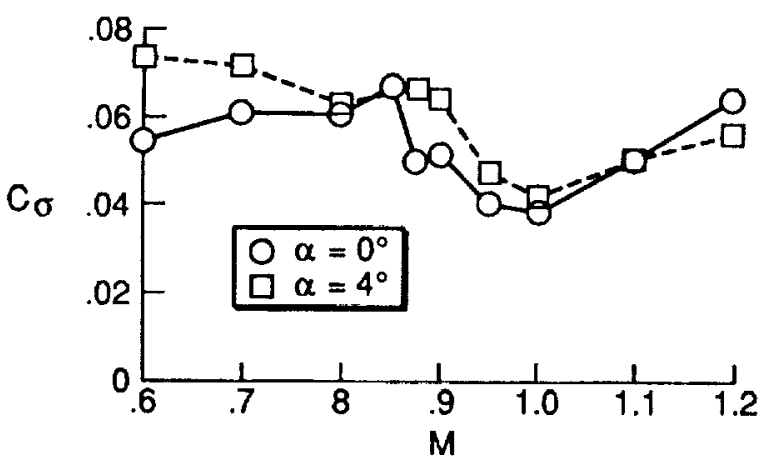

Fig. 13- Effects of $M$ and $\alpha$ on $\sigma$ measured at the pivot point for the first bending mode configuration with vertical stiffening rods installed.

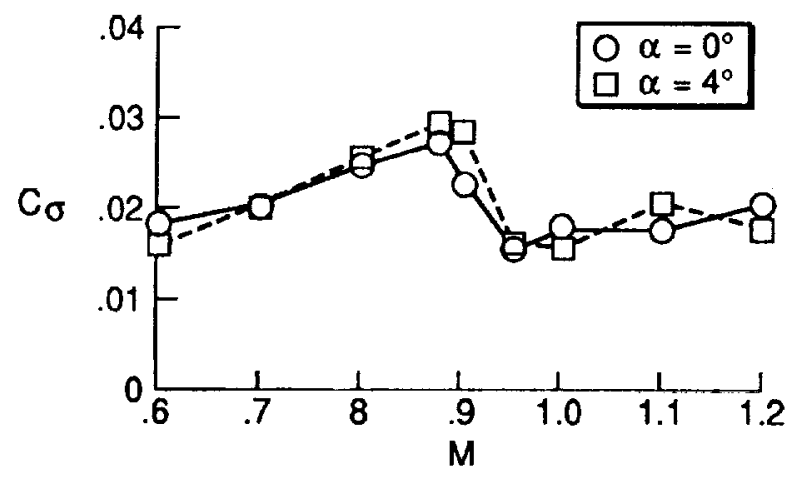

Fig. 14- Effects of $M$ and $\alpha$ on $\sigma$ measured at the pivot point for the second bending mode configuration without the vertical stiffening rods installed.

\section{Angle-of-Attack Variations}

Root-mean-square bending moment response measurements were made for $\alpha=0.0^{\circ}$ and for $\alpha=4.0^{\circ}$ for both of the Atlas-I LPF vibration mode configurations. Figure 13 shows typical root-mean-square bending moments as angle of attack and Mach number are varied for the $L / D=1.0$ (rods-installed), first bending mode configuration. Figure 14 shows similar results for the $\mathrm{L} / \mathrm{D}=1.0$, second bending mode configuration without the vertical stiffening rods installed. The first bending mode configuration is shown to be more sensitive to the angleof-attack variation than the second bending mode configuration. For both modes, the model response was more dependent on Mach number variations than angle of atlack for the range of conditions tested.

\section{Wind-Tunnel Influence}

Because the response of the Atlas-I LPF model continued to increase above $\mathrm{M}=1.0$, some effort was made to assess the influence of the vibration levels associated with the wind-tunnel facility. Figure 15 shows measured vertical accelcration response of the wind-tunnel support sector ${ }^{*}$ without the model or sting installed. Figure 15 secms to be consistent with observations from oscillatory now studies conducted in the TDT (using large flow vanes upstream of the test section to force oscillatory tunnel flow) which noted significant tunnel resonance effects above $10 \mathrm{~Hz}$. 7,8 The autospectrum frequency response function shown in this figure (for $M=1.2$ ) clearly indicates two response peaks corresponding to approximately $10 \mathrm{~Hz}$ and $26 \mathrm{~Hz}$. These two frequencies are nearly the same values as those of the first bending and second bending mode configurations of the wind-tunnel model. Thercfore, it is possible that the measured model response, while still at acceptable levels for the flight vehicle based on any of the model configurations, may actually be intensified by the wind-tunnel support sector response at the same frequencics. Figure 16 shows normalized sting sector response as a function of Mach number. Some preliminary examination has indicated the possibility of a strong relationship between the wind-tunncl drive system total power consumption and fan rotational specd and the measured sting support sector vibratory response. Regardless of the source, figure $\mathbf{1 6}$ shows that the facility vibration continues to grow for any increase in Mach number with the rate of increase becoming even greater above $M=1.0$. This suggests there may be a much stronger influence on the model response above $\mathrm{M}=1.0$.

* The term "support sector" is used to describe the physical structure built into the TDT test section to support models mounted on a sting at the vertical centerline of the tunnel test section. The support sector in the TDT is constructed so that the model can be remotely pitched and traversed vertically in the test section. 
Since the buffet response of the wind-tunnel model was not severe for any of the configurations tested, the influence of the tunnel response may have been great enough to somewhat hide the expected peak response in the transonic region as discussed in the preceding $L / D$ variations sub-section. Based on these test results, however, the buffet response data above $M=1.0$ was not used to define vehicle design loads.

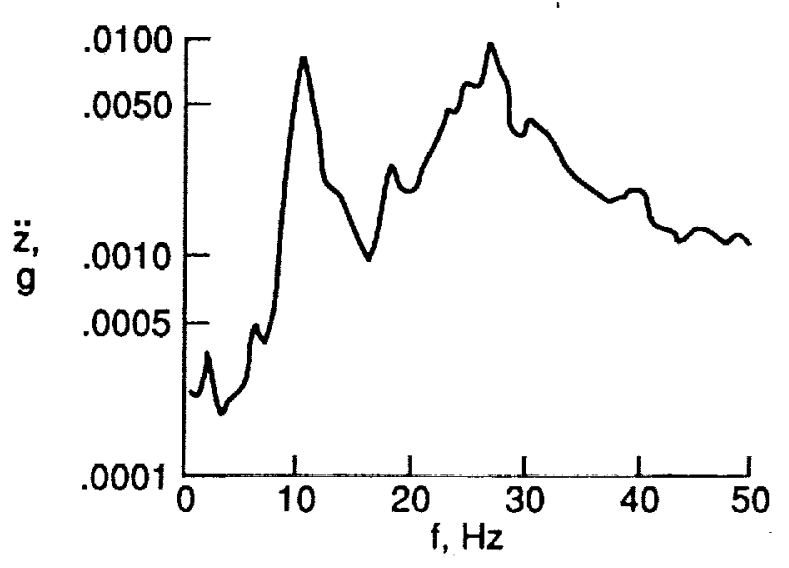

Fig. 15- Empty wind-tunnel frequency response function measured on the sting support sector $(M=1.2)$.

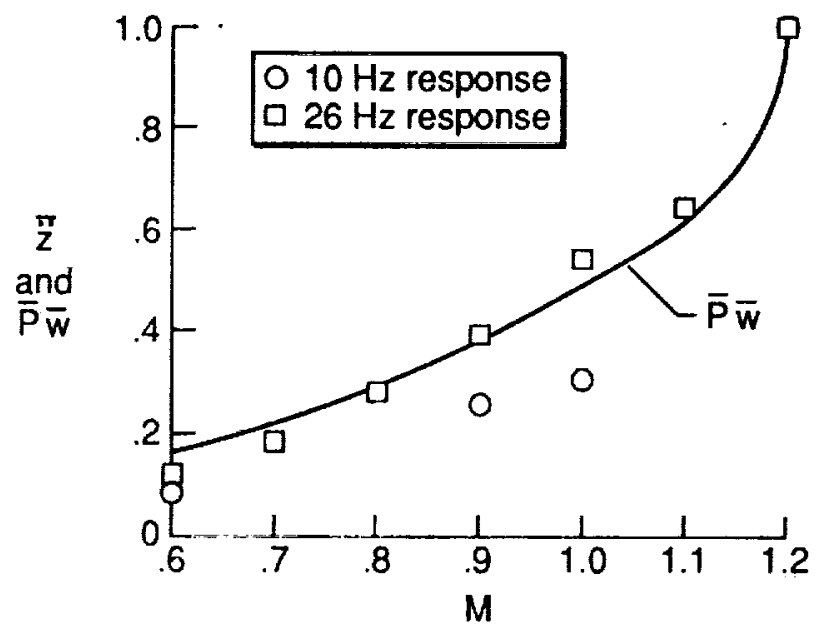

Iig. 16- Normalized support sector vertical response without model or sting mounted in wind tunnel.

Figure 17 shows a comparison of the model responses of the $L / D=1.0$ configuration for the support rods installed and not installed. These vertical stiffening rods would be expected to help overcome the influence of the facility vibrations through the sting support sector. The lower response of the rods-installed configuration suggests that the influence of the facility vibration is indeed less. Further, with the rods installed, the model exhibits a much more distinct transonic peak, although the response still continues to increase beyond $M=1.0$. The rods-installed configuration of figure 17 could perhaps be considered the best characterization of the model buffet response (least influenced by the facility) and the difference between the response of the rod-installed and the rods-notinstalled configurations could be considered a portion of the measured response error due to the influence of the facility. Under these assumptions, the response error could be applied to the data of figure 11 and then each of the L/D conligurations for the first bending mode model would exhibit a much more distinct transonic response pcak.

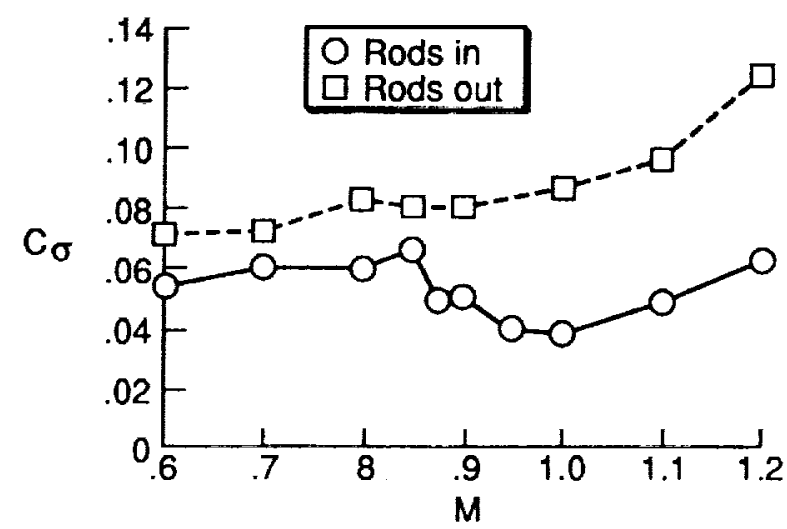

Fig. 17- Buffet response for the $L / D=1.0$ payload fairing in the first bending mode configuration with and without the vertical stiffening rods installed.

\section{Elight Yehicle Comparison}

The first flight of the Atlas-Centaur I vehicle successfully occurred on July 25,1990 . Some strain gauge data werc acquired from this initial flight which can be compared with results from the wind-tunnel test. This comparison is shown in figure 18 . The wind-tunnel results are for the $L / D=1.0$, first bending mode simulation configuration with the vertical stiffening rods installed. This configuration is considered to be the best available simulation of the Might vehicle. The coefficient $\mathrm{C}_{\sigma}$ shown for the wind-tunnel model in figure 18 has been scaled to full-scale flight data and adjusted to represent the same body station as that measured in flight. Since the majority (greater than 95 percent) of the flight bending moment response at this station was found to be attributed to the first vehicle bending mode, it can be directly compared to the narrow-band response of the wind-tunncl model in the first bending mode configuration.

The first mode root-mean-squarc bending moments $(\sigma)$ used in the calculation of $\mathrm{C}_{\sigma}$ for the wind-tunnel model were obtained based on relatively long time responses at constant tunnel conditions. Furthermore, through analysis of typical wind-tunnel data it was determined that the narrow-band frequency response near the first bending mode closely matches a probability density function ${ }^{9}$ for a normal (Gaussian) random process. Based on these considerations the probability that an 
instantaneous value of the bending moment will ever exceed $3 \sigma$ is very small. Reference 9 shows that the probability for an instantaneous value of the bending moment to be less than $3 \sigma$ is 99.9 percent, less than $2 \sigma$ is 97.7 percent, and less than $1 \sigma$ is 84.1 percent. This statistical information for the wind-tunnel model is useful in trying to assess the comparison with the flight data. The flight data shown in figure 18 represents pcak values at rather rapidly changing Mach numbers during the vehicle atmospheric ascent. These peak-value bending moment coefficients cannot be compared to the windtunnel rool-mean-square bending moments with any absolute certainty. Approximately 60 seconds of data was taken at any single Mach number during the wind-tunnel test compared to the full-scale vehicle passing through the peak response region $(0.75<\mathrm{M}<0.90)$ in approximately six seconds. Assuming that the flight data also approximates a normal random process, then it can be said that the flight data is well below the $3 \sigma$ level determined by the wind-tunnel model, as would be expected. Although no proper conclusion can be drawn from this observation, it is interesting to note that the peak response flight data gencrally occurred near the $1 \sigma$ level of the wind-tunnel model.

The flight data indicates a slight peak in the buffet response at approximately $M=0.73$. The wind-tunnel data peaked at a higher Mach number condition, approximately $M=0.85$. As previously discussed the wind-tunnel model response continues to increase beyond $M=1.0$, possibly due to the influence of wind-tunnel facility mechanical vibration. In comparison, the Mlight data tends to consistently decrease beyond $\mathrm{M}=1.0$ as was expected based on past experiences with launch vehicles.

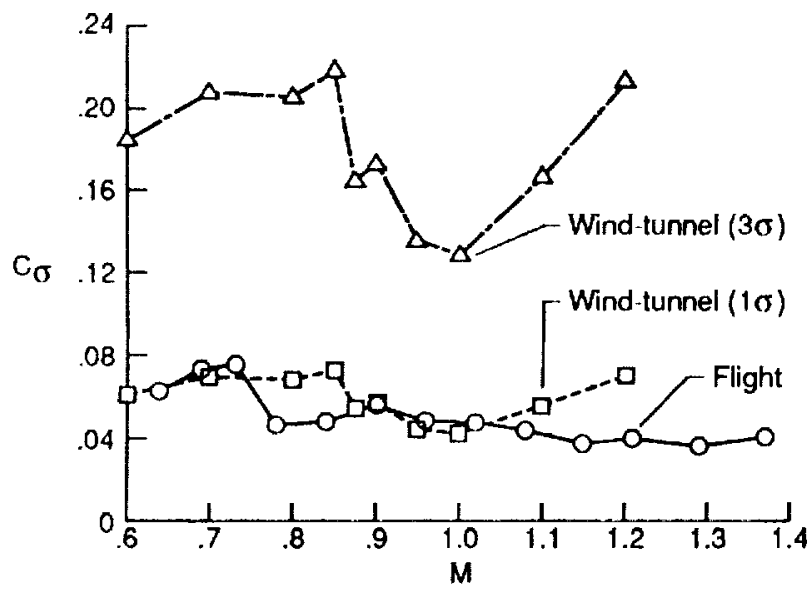

Fig. 18- Comparison of flight mcasurements with scalcd wind-tunnel test measurements. ( $\mathrm{L} / \mathrm{D}=1.0$, first bending mode configuration with vertical stiffening rods installed.)

\section{Concluding Remarks}

A wind-tunnel test of the Atlas-I Large Payload Fairing configuration has been conducted in the Langley Transonic Dynamics Tunnel. The wind-tunnel model was acroclastically scaled from the flight vehicle. A partial mode construction technique was used to simulate the first two bending modes of the flight vehicle. Buffet response characteristics and dynamic stability of the vehicle have been assessed through the wind-tunnel test. The windtunnel results indicated that the flight vehicle would be free of dynamic instabilities and that the buffet loads would be less than ten percent of the total vehicle design load at all flight conditions. In addition to the flight clearance studies, angle-of-attack and payload fairing L/D variations were lested.

The following statements summarize the most significant findings from the wind-tunnel test:

1) The buffet response level was not significantly affected by $L / D$ variations except for the $L / D=0.3$ fairing in the second bending mode configuration. For the $L / D=0.3$ configuration, the transonic buffet response was much greater than for the other $\mathrm{L} / \mathrm{D}$ ratios tested in the sccond bending mode configuration.

2) The wind-tunnel model response was not very sensitive to angle of attack for the conditions tested. The variation in buffet response due to Mach number changes was of greater influence than that due to angle of attack changes.

3) The sting support sector vibration most likely increased the apparent buffet responsc. This influence of the tunnel installation appears to become even greater above $M=1.0$. Vertical stiffening rods were installed on the sting support sector to help alleviate these undesirable vibrations for the configurations representing the nominal night vehicle.

4) Peak bending moment measurements from the first flight of the Atlas-I LPF vehicle have been compared with root-mean-square bending moments measured in the wind tunnel. These data show that the peak flight bending moments were well below the $3 \sigma$ level of the wind-tunnel data, correspond closcly to the $1 \sigma$ buffet levels of the wind-tunnel model, and level off above $\mathrm{M}=1.0$. 


\section{References}

1) Cole, Henry A., Jr.; Erickson, A. L.; and Rainey, A. G.: Buffeting During Atmospheric Ascent. NASA SP-8001, 1963, Revised November 1970.

2) Bombardier, G. D.: Final Post-Test Report on Seven Percent Transonic Buffet Model for Various Titan III Configurations. Martin Co. Report Number SSDCR-66-563, January 1967.

3) de Azcvedo, Joåo L. F.: Transonic Acroelastic Analysis of Launch Vehicle Configurations. NASA CR 4186, 1988.

4) Reed, Wilmer H.: Acroclasticity Matters: Some Reflections of Two Decades of Testing in the NASA Langley Research Tunnel. NASA TM-83210, 1981.

5) Cole, Henry A.,Jr.: Dynamic Response of Hammerhead Launch Vehicles to Transonic Buffeting. NASA TN D-1982, 1963.
6) Ericsson, L. E., and Reding, J. P.; Fluid Dynamics of Unsteady Separated Flow. Part I. Bodies of Rcvolution. Progress in Aerospace Science, Vol. 23, 1986, pp. 1-84.

7) Mirick, Paul H., Hamouda, M-Nabil H., Yeagcr, William T., Jr.: Wind-Tunnel Survey of an Oscillating Flow Ficld for Application to Model Helicopter Rotor Testing. NASA TM 4224, 1990.

8) Abbott, Frank T., Jr.: Brief Description of the Characteristics of the Langley Transonic Dynamics Tunncl Airstream Oscillator. Meeting on Aircraft Response to Turbulence, NASA TM-82340, 1968, pp. 6.1-6.11.

9) Curtis, Allen J.: Concepts in Vibration Data Analysis. Harris, Cyril M. and Crede, Charles E. (editors): Shock and Vibration Handbook. McGrawHill Book Co., New York, NY, 1976, pp. 22-1 to 22-28. 


\begin{tabular}{|c|c|c|c|}
\hline \multicolumn{4}{|c|}{ Report Documentation Page } \\
\hline $\begin{array}{l}\text { 1. Repor No. } \\
\text { NASA TM-104050 }\end{array}$ & 2. Government Accession No. & \multicolumn{2}{|c|}{ 3. Recipient's Catalog No. } \\
\hline \multirow{2}{*}{\multicolumn{2}{|c|}{$\begin{array}{l}\text { 4. Titte and Subtitle } \\
\text { Dynamic Response of a Hammerhead Launch Vehicle } \\
\text { Wind-Tunnel Model }\end{array}$}} & \multicolumn{2}{|c|}{$\begin{array}{l}\text { 5. Report Date } \\
\text { February } 1991\end{array}$} \\
\hline & & \multicolumn{2}{|c|}{ 6. Performing Organization Code } \\
\hline \multirow{3}{*}{\multicolumn{2}{|c|}{$\begin{array}{l}\text { 7. Author(s) } \\
\text { Stanley R. Cole and Thomas L. Henning }\end{array}$}} & \multirow{2}{*}{\multicolumn{2}{|c|}{ 8. Performing Organization Repon No. }} \\
\hline & & & \\
\hline & & \multicolumn{2}{|c|}{$\begin{array}{l}\text { 10. Work Unit No. } \\
505-63-50-13\end{array}$} \\
\hline \multicolumn{2}{|l|}{$\begin{array}{l}\text { NASA Langley Research Center } \\
\text { Hampton, Virginia } 23665-5225\end{array}$} & \multicolumn{2}{|c|}{ 11. Contract or Grant No. } \\
\hline \multirow{2}{*}{\multicolumn{2}{|c|}{$\begin{array}{l}\text { 12. Sponsoring Agency Name and Addrees } \\
\text { National Aeronautics and Space Administration } \\
\text { Washington, DC } 20546-0001\end{array}$}} & \multicolumn{2}{|c|}{$\begin{array}{l}\text { 13. Type of Report and Period Covered } \\
\text { Technical Memorandum }\end{array}$} \\
\hline & & \multicolumn{2}{|c|}{ 14. Sponsoring Agency Code } \\
\hline \multicolumn{4}{|c|}{$\begin{array}{l}\text { Thomas L. Henning is employed by General Dynamics Space Systems Division, San Diego, CA. This work was conducted } \\
\text { in the Langley TDT under a Memorandum of Agreement with General Dynamics. } \\
\text { This paper will also be presented at the 32nd Structures, Structural Dynamics and Materials Conference in Baltimore, } \\
\text { Maryland, on April 8-10, } 1991 \text {. }\end{array}$} \\
\hline \multicolumn{4}{|c|}{$\begin{array}{l}\text { 16. Abstract } \\
\text { A wind-tunnel test of a 1/10th-scale Atlas-Centaur I Large Payload Fairing launch vehicle model has been conducted in the } \\
\text { NASA Langley Transonic Dynamics Tunnel. The wind-tunnel model was an acroclastically-scaled version of the flight vehicle } \\
\text { and was capable of simulating either of the first two bending vibration modes of the full-scale vehicle by a partial mode technique. } \\
\text { The primary purpose of the test was to gather data concerning buffet response which could be used to clear the vehicle for flight. } \\
\text { Additionally, angle-of-attack studies were conducled and several payload fairing configurations were tested to assess the buffet } \\
\text { response and dynamic stability of off-design flight conditions and geometric parameters. No dynamic instabilities were found } \\
\text { for any of the configurations tested. The buffet response data for the nominal flight configuration indicate that the unsteady buffet } \\
\text { loads represent } 5 \text {-10 percent of the total design load and, therefore, the buffet loads are not a large factor affecting the overall } \\
\text { vehicle design. Payload fairing length-to-diameter ratio variations were found to have small effects on the buffet response of the } \\
\text { model, except in the case of the smallest length-to-diameter ratio in the second bending mode configuration. This configuration } \\
\text { experienced much greater transonic buffeting relative to the other length-to-diameter models for the second bending mode } \\
\text { simulation. The effects of angle of attack on buffet response were found to be small. The model was more sensitive to Mach } \\
\text { number changes than to angle of atlack. The buffet response results from this wind-tunnel test were influenced by the tunnel } \\
\text { facility vibration levels. An attempt was made to experimentally reduce the effect of the facility mechanical vibration for the } \\
\text { nominal flight configuration by testing with vertical rods used to stiffen the sting support. The first flight of the Atlas-Centaur } \\
\text { I vehicle successfully occurred on July } 25,1990 \text {, and a comparison of light measurements with wind-tunnel data is presented } \\
\text { in this paper. The flight data was found to be well within the } 3 \sigma \text { level of the wind-tunnel data. }\end{array}$} \\
\hline $\begin{array}{l}\text { 17. Key Words ISuggesiod by Author(s) } \\
\text { Buffet } \\
\text { Launch Vehicle } \\
\text { Acroclasticity }\end{array}$ & 18. Dist & Uory -15 & \\
\hline $\begin{array}{l}\text { 19. Socurity Classit. (of this report) } \\
\text { Unclassified }\end{array}$ & $\begin{array}{l}\text { 20. Socurity Classif. (of this poge) } \\
\text { Unclassified }\end{array}$ & $\begin{array}{c}\text { 21. No. of pages } \\
11\end{array}$ & $\begin{array}{r}\text { 22. Price } \\
\mathrm{A} 03\end{array}$ \\
\hline
\end{tabular}

